\title{
Bilateral Thalamic Metastases in Endometrial Adenocarcinoma
}

\author{
Carole Ramirez $^{\mathrm{a}} \quad$ Nicolas Reyns $^{\mathrm{a}} \quad$ David Pasquier $^{\mathrm{b}} \quad$ Serge Blond $^{\mathrm{a}}$ \\ ${ }^{a}$ Neurosurgery Department, R. Salengro Hospital, and b Radiotherapy Department, Centre Oscar Lambret, \\ Lille University Medical Center, Lille, France
}

A 61-year-old woman presented with dysesthesia of the face and upper limbs, memory impairment and apathy. $\mathrm{T}_{1}$-weighted MRI showed mass lesions in both thalami (fig. 1). Her medical history included a stage IIB grade III endometrial cancer treated with surgery and radiotherapy 1 year earlier. Whole-body search for metastases was negative. Stereotactic biopsies confirmed the metastatic nature of the thalamic lesions (fig. 2). Radiotherapy resulted in improvement of the neurological and imaging conditions, but the patient died from pulmonary embolism 17 months after the diagnosis of brain metastases.

Metastases confined to the thalami have seldom been reported [1], and bilateral localization of endometrial adenocarcinoma is exceptional.

\section{Reference $\quad 1$ Sherman JD, Kager CD, Ward J, Warnick RE, Breneman JC: Stereotactic radiosurgery for brainstem and thalamic metastases. J Radio- surgery 2000;3:133-138.}

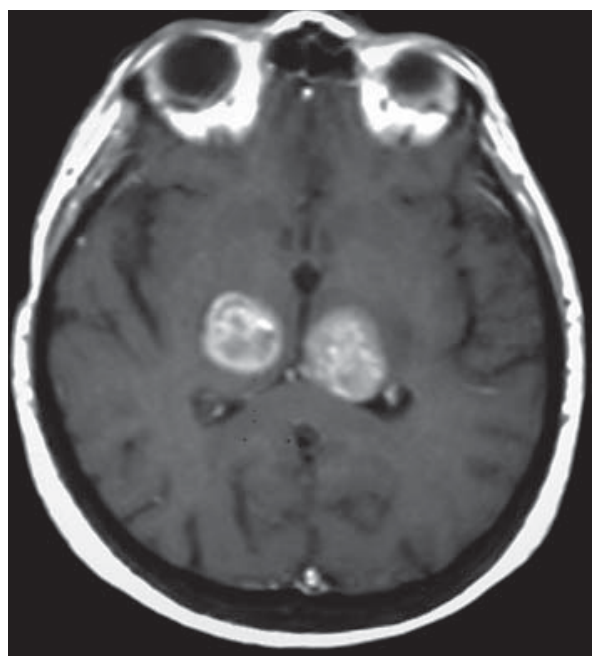

Fig. 1. $\mathrm{T}_{1}$-weighted brain MRI with gadolinium enhancement: bilateral thalamic lesions with surrounding edema.

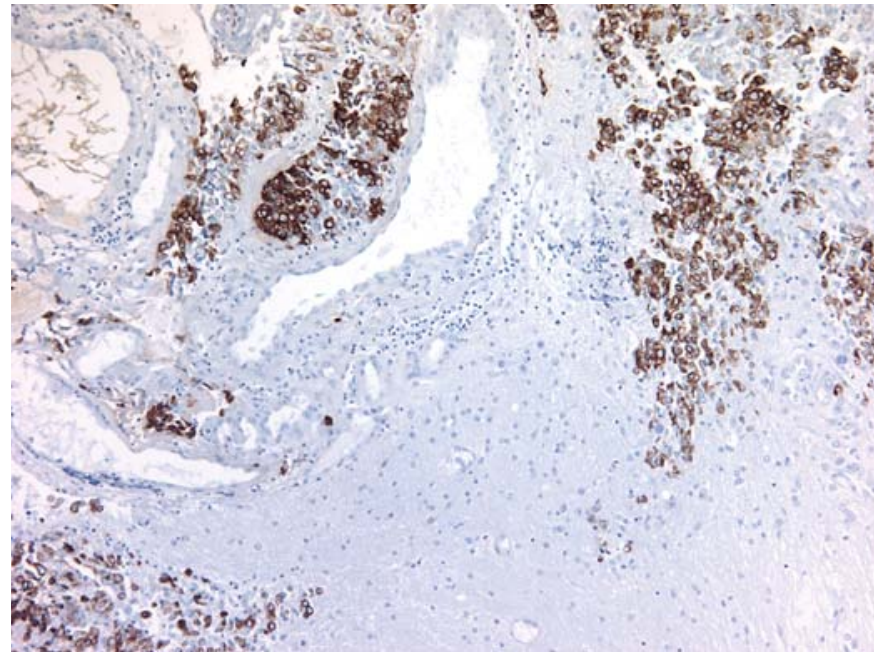

Fig. 2. Histopathological examination: immunostaining of cytokeratin 7 in tumor cells.

\section{KARGER}

Fax +41613061234 E-Mail karger@karger.ch www.karger.com
() 2008 S. Karger AG, Basel

0014-3022/08/0596-0330\$24.50/0

Accessible online at:

www.karger.com/ene
Carole Ramirez, MD

Service de Neurochirurgie, Hôpital Roger Salengro, CHRU de Lille Rue Emile Laine

FR-59037 Lille Cedex (France)

Tel. +33 662 133 701, Fax +33 320446 808, E-Mail c-ramirez@chru-lille.fr 